\title{
Hepatocellular carcinoma chemoprevention in chronic hepatitis B patients: all-in on statins?
}

\author{
José Ursic-Bedoya ${ }^{1}$, Boris Guiu ${ }^{2}$ \\ ${ }^{1}$ Department of Hepatology, ${ }^{2}$ Department of Radiology, St-Eloi University Hospital, Montpellier, France \\ Correspondence to: Prof. Boris Guiu, MD, PhD. Department of Radiology, St-Eloi University Hospital, 80 Avenue Augustin Fliche, 34295 Montpellier, \\ France. Email: B-guiu@chu-montpellier.fr. \\ Comment on: Goh MJ, Sinn DH, Kim S, et al. Statin Use and the Risk of Hepatocellular Carcinoma in Patients With Chronic Hepatitis B. \\ Hepatology 2020;71:2023-32.
}

Submitted Feb 16, 2020. Accepted for publication Mar 14, 2020.

doi: 10.21037/hbsn.2020.03.06

View this article at: http://dx.doi.org/10.21037/hbsn.2020.03.06

Chronic hepatitis B (CHB) affects approximately 257 million individuals worldwide, the highest prevalence being in Western Pacific WHO Region [6.2\% (1)]. In highly endemic CHB regions, the 5 -year cumulative incidence of hepatocellular carcinoma (HCC) ranges from $3 \%$ to $17 \%$, depending on the presence of cirrhosis (2). Antiviral treatment decreases the risk of HCC, without abolishing it completely (3). Paradoxically, by decreasing liver-related mortality, antiviral treatment in CHB patients causes an increase in HCC long-term incidence (4).

Thus, prevention of HCC development in high-risk patients is theoretically an impactful strategy to improve patient prognosis. However, no such therapy has been established to date, despite some promising candidates. Diverse molecules such as aspirin, metformin, caffeine, antifibrotic therapies and statins have shown decreased hazardratios (HR) of HCC in high-risk populations (5).

The rationale behind statins use to prevent cancer lies in the biological pathways implicated in the response to statins. In experimental HCC models, statins showed inhibition of proto-oncogene Myc (6), AKT phosphorylation (7), nuclear factor- $\kappa \beta(\mathrm{NF \kappa} \beta)$ and tumour necrosis factor (TNF)-mediated interleukin 6 production (8). Numerous (and heterogeneous) observational studies on statins have suggested a decrease in HCC incidence in different settings of chronic liver disease. A meta-analysis (9) published in 2013 estimated a $41 \%$ decrease in HCC incidence in patients treated with statins, although between 57 (high-risk HBV positive population) and 5,209 (lower-risk population) patients needed to be treated in order to prevent one case of HCC. Although some concerns were raised over safety of statins in patients with chronic liver disease, it has been shown in a randomized trial that statin-induced hepatotoxicity was lower than expected (10).

However, many questions arise: is the beneficial effect of statins HCC chemoprevention applicable to all statins? Is there a minimal dose or length of exposure to statins? Is this strategy applicable to all subgroups of patients?

In a future issue of Hepatology, Goh et al. (11) report on their unique cohort of more than 7,000 CHB patients followed in Samsung Medical Center (Seoul, Korea). Their work aimed to examine the association between statin use and the risk of incident HCC in this high-risk cohort, by adjusting on important potential risk factors. Focusing on predefined subgroups of patients and the cumulative exposure to statins (defined by the cumulative defined daily dose or cDDD), this study brings up new evidence in favor of statins HCC chemoprevention.

One of the main findings of the study lies in the low adjusted HR of 0.36 (95\% CI: 0.19-0.68) associated with statin use, almost as low as that achieved with antiviral treatment (0.27, 95\% CI: 0.23-0.32). The association with statin use and lower risk of HCC development applies especially for lipophilic statins [HR (95\% CI), 0.35 (0.16-0.78)] such as atorvastatin, simvastatin, pitavastatin and fluvastatin, whereas marginal statistical significance was observed for hydrophilic statins. Furthermore, a clear dose-response relationship was found, based on cDDD. Finally, the association between statin use and HCC development was confirmed in predefined subgroup analyses. 
The strength of this study lies in (I) the long followup period (median 7.2 years), (II) the large number of incident HCC cases (702 cases, $9.1 \%$ of the cohort) and (III) adjustments on potential risk factor for HCC development and especially liver cirrhosis, serum HBV DNA levels and anti-viral treatment.

Nevertheless, these findings must be tempered by some of the limitations of this study. It is a retrospective single-center study which focuses on an extremely peculiar population: the predominant HBV genotype in Korea is $\mathrm{C}$, which is associated with a higher-risk of HCC when compared to other genotypes (12). As acknowledged by the authors, this study calls for external validation studies in other ethnicities and in other HBV genotypes.

Is this study sufficient to infer causality between statin use and HCC chemoprevention? Certainly not, even though it adds another brick in the wall of statin recommendation in patients at a high-risk for HCC. A final response should come from the numerous currently ongoing or recently terminated prospective trials.

\section{Acknowledgments}

Funding: None.

\section{Footnote}

Provenance and Peer Review: This article was commissioned by the editorial office, Hepatobiliary Surgery and Nutrition. The article did not undergo external peer review.

Conflicts of Interest: Both authors have completed the ICMJE uniform disclosure form (available at http://dx.doi. org/10.21037/hbsn.2020.03.06). The authors have no conflicts of interest to declare.

Ethical Statement: The authors are accountable for all aspects of the work in ensuring that questions related to the accuracy or integrity of any part of the work are appropriately investigated and resolved.

Open Access Statement: This is an Open Access article distributed in accordance with the Creative Commons Attribution-NonCommercial-NoDerivs 4.0 International License (CC BY-NC-ND 4.0), which permits the noncommercial replication and distribution of the article with the strict proviso that no changes or edits are made and the original work is properly cited (including links to both the formal publication through the relevant DOI and the license). See: https://creativecommons.org/licenses/by-nc-nd/4.0/.

\section{References}

1. Seto WK, Lo YR, Pawlotsky JM, et al. Chronic hepatitis B virus infection. Lancet 2018;392:2313-24.

2. Fattovich G, Bortolotti F, Donato F. Natural history of chronic hepatitis B: special emphasis on disease progression and prognostic factors. J Hepatol 2008;48:335-52.

3. Wu CY, Lin JT, Ho HJ, et al. Association of nucleos $(\mathrm{t})$ ide analogue therapy with reduced risk of hepatocellular carcinoma in patients with chronic hepatitis B: a nationwide cohort study. Gastroenterology 2014;147:14351.e5.

4. Choi J, Han S, Kim N, et al. Increasing burden of liver cancer despite extensive use of antiviral agents in a hepatitis B virus-endemic population. Hepatology 2017;66:1454-63.

5. Fujiwara N, Friedman SL, Goossens N, et al. Risk factors and prevention of hepatocellular carcinoma in the era of precision medicine. J Hepatol 2018;68:526-49.

6. Cao H, Mi L, Ye Q, et al. Purification and characterization of a novel NADH-dependent carbonyl reductase from Pichia stipitis involved in biosynthesis of optically pure ethyl (S)-4-chloro-3-hydroxybutanoate. Bioresour Technol 2011;102:1733-9.

7. Ghalali A, Martin-Renedo J, Hogberg J, et al. Atorvastatin Decreases HBx-Induced Phospho-Akt in Hepatocytes via P2X Receptors. Mol Cancer Res 2017;15:714-22.

8. Wang J, Tokoro T, Higa S, et al. Anti-inflammatory effect of pitavastatin on NF-kappaB activated by TNFalpha in hepatocellular carcinoma cells. Biol Pharm Bull 2006;29:634-9.

9. Singh S, Singh PP, Singh AG, et al. Statins are associated with a reduced risk of hepatocellular cancer: a systematic review and meta-analysis. Gastroenterology 2013;144:323-32.

10. Lewis JH, Mortensen ME, Zweig S, et al. Efficacy and safety of high-dose pravastatin in hypercholesterolemic patients with well-compensated chronic liver disease: Results of a prospective, randomized, double-blind, placebo-controlled, multicenter trial. Hepatology 2007;46:1453-63.

11. Goh MJ, Sinn DH, Kim S, et al. Statin Use and the Risk 
of Hepatocellular Carcinoma in Patients With Chronic Hepatitis B. Hepatology 2020;71:2023-32.

12. Tseng TC, Liu CJ, Yang HC, et al. High levels of hepatitis
B surface antigen increase risk of hepatocellular carcinoma in patients with low HBV load. Gastroenterology 2012;142:1140-9.e3; quiz e13-4.
Cite this article as: Ursic-Bedoya J, Guiu B. Hepatocellular carcinoma chemoprevention in chronic hepatitis B patients: allin on statins? HepatoBiliary Surg Nutr 2020;9(5):676-678. doi: 10.21037/hbsn.2020.03.06 